\title{
Air weapon injuries in children: a case for education
}

\author{
W. JOAN ROBSON AND K. KUMAR* \\ Accident and Emergency Department, Alder Hey Children's Hospital, \\ Liverpool, England
}

\section{SUMMARY}

The results of the first 6 months of a 2-year prospective study on the frequency, severity and methods of prevention of air weapon injuries to children are reported. Twenty-eight cases presenting to an urban paediatric accident and emergency department have been analysed. Nineteen of these were males between the ages of 10 and 16 years. At least 18 incidents occurred in public places. The five most serious injuries were of the orbit, face and abdomen. Another nine injuries were near vital structures. Education is needed on the existing guidelines for the safe use of air weapons.

\section{INTRODUCTION}

Injuries due to violence against children lead to concern among all their care-givers. In a 4-week period beginning in February 1983, eight children between the ages of 4 and 15 years attended the Accident and Emergency Department at Alder Hey Children's Hospital, Liverpool with injuries caused by misuse of air weapons. Enquiries revealed that parents, doctors, teachers, police officers, politicians and members of sporting associations were all aware of increasing problems caused by a small percentage of irresponsible owners. A prospective study over 2 years was therefore planned. The aims of the study were to assess the incidence and severity of air weapon injuries in children and to look for ways of preventing these injuries. In November 1983 a Home Office campaign called 'Gun sense is good sense' was launched to improve education on the correct use of air weapons, so an interim report on the first 6 months of this study is appropriate.

\footnotetext{
*Present address: Milton Keynes Hospital, Standing Way, Eaglestone, Milton Keynes, MK6 5AZ, England
}

Correspondence: Miss W. Foan Robson, Accident and Emergency Department, Alder Hey Children's Hospital, Eaton Road, Liverpool, L12 2AP, England 


\section{PATIENTS AND METHODS}

The study included all patients between the ages of 0 and 16 years who presented to the $\frac{3}{0}$ department on or after 1 March 1983 with a history of injury from an air weapon or? radiological evidence of an airgun pellet. Data were collected at the time of injury and at follow-up attendances. Sex and age of patients, details of incident, site of injury, presence of pellets, treatment and short-term disability were recorded.

\section{RESULTS}

From 1 March to 31 August 1983 there were 28 individual patients with air weapon injury, of whom 25 were boys. Their ages ranged from 3 to 16 years. The majority (21) . were over the age of 10 years and were boys (19). Not one patient admitted to handling aiv gun at the time of injury. The details of the incidents leading to injury were sometimes difficult to obtain but on at least two occasions air weapons were being used in homes. However, most shootings occurred in public places (18). In eight cases details of the incident were very vague.

The site of injury was the head in nine patients (including three orbital injuries), the neck in one, the chest in two, the abdomen in two, the lumbar region in one, the upper? limb in six and the lower limb in seven. In half the patients pellets were demonstrated 000 on radiographs at the time of attendance. These were diabolo-shaped (Fig. 1a) in $\frac{93}{3}$ incidents. One was a Prometheus-type with bullet-shaped head (Fig. 1b).

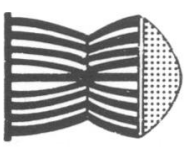

A.

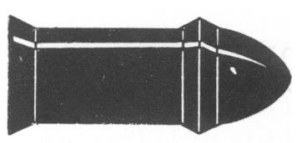

B.

Fig. 1 A Diabolo pellet; B Prometheus pellet.

Minor injuries were present in 20 patients. Of those who did not have pellets demonstrated 13 had abrasions, puncture wounds and/or haematomata at the site of impact. In two patients pellets were in the scalp. Others had pellets in the subcutaneous tissues of the nose, neck, chest and wrist respectively. One patient had a pelle? embedded in the tip of the ring finger and had a fracture of the terminal phalanx (Fign 2). All pellets in these patients were removed under local anaesthesia by staff of the Accident and Emergency Department.

Major injuries were sustained by five patients. One boy developed a concussion cataract of the eye. In another a pellet was embedded in the optic nerve (Fig. 3), giving unilateral blindness; it was left in situ. Pellets in the maxillary antrum (Fig. 4), extenso 


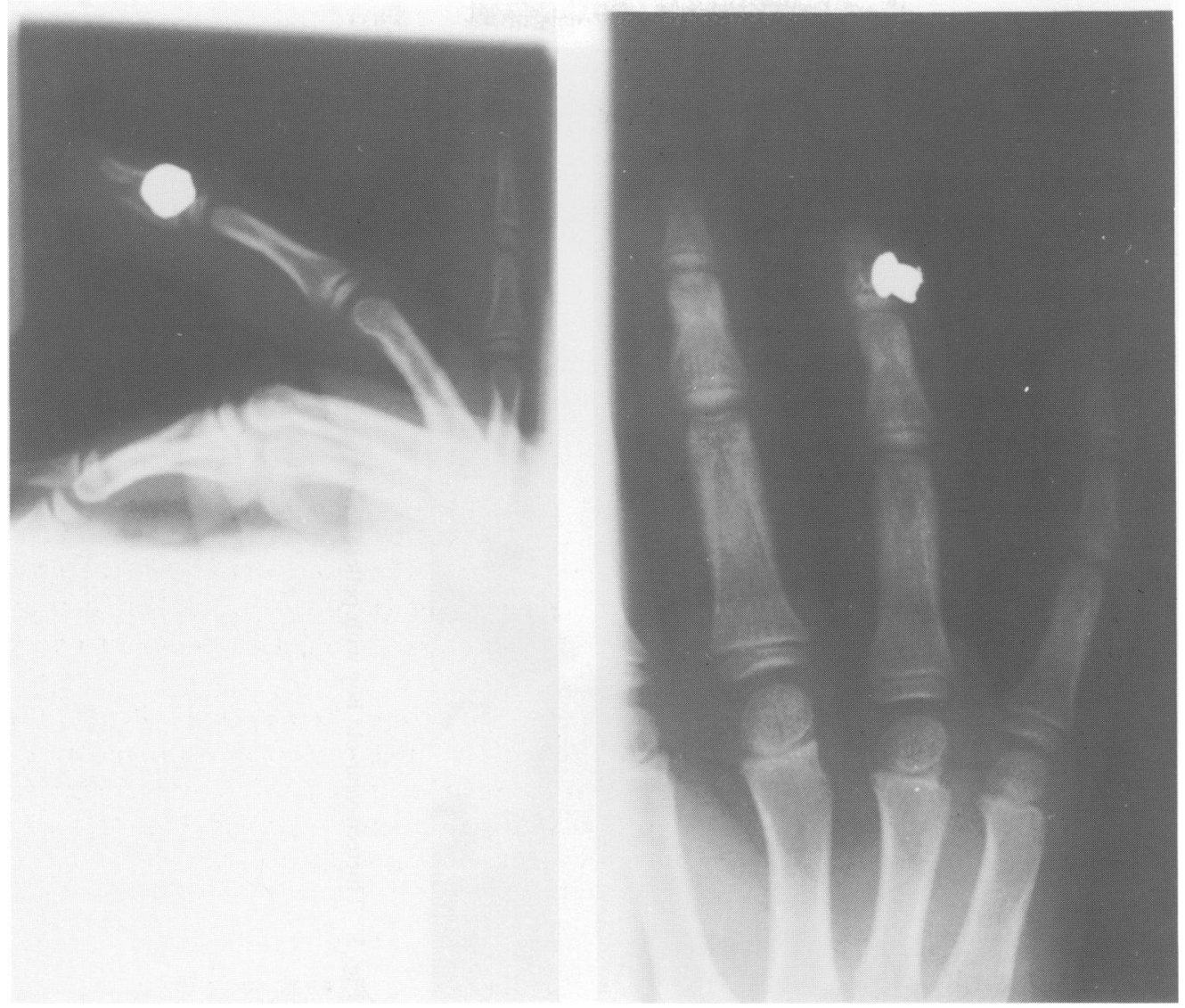

Fig. 2 Twelve-year-old boy with pellet in right ring finger with fracture of distal phalanx. Removed under local anaesthesia.

tendon of the hand, ligamentum patellae, and upper abdomen (Fig. 5) were removed under general anaesthesia by paediatric surgeons. The latter gave the only lifethreatening injury in the series. The pellet had passed through the jejunum, $6 \mathrm{~cm}$ from the duodenojejunal junction and was lodged in the small bowel mesentery. The perforations were sutured at the time of removal of the pellet.

The other two patients had pellets embedded deeply in the orbit and in the muscles of the thigh respectively. Neither affected vital structures so they were left in situ.

Six patients $(21 \%)$ have residual disability. Permanent unilateral blindness and concussion cataract are two major consequences of the injuries in this study. At the time of reporting two patients have residual pain at the site of injury and two others have minor musculoskeletal problems, all of which should resolve in time. 


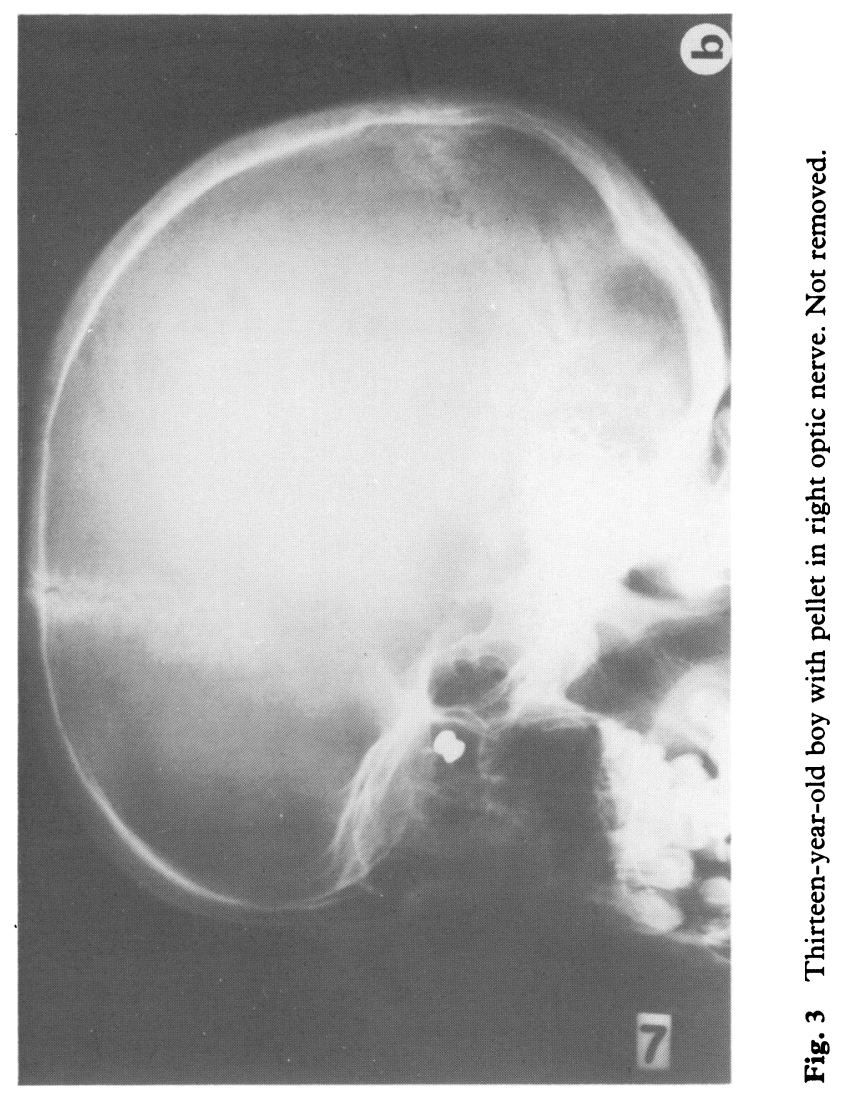

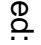

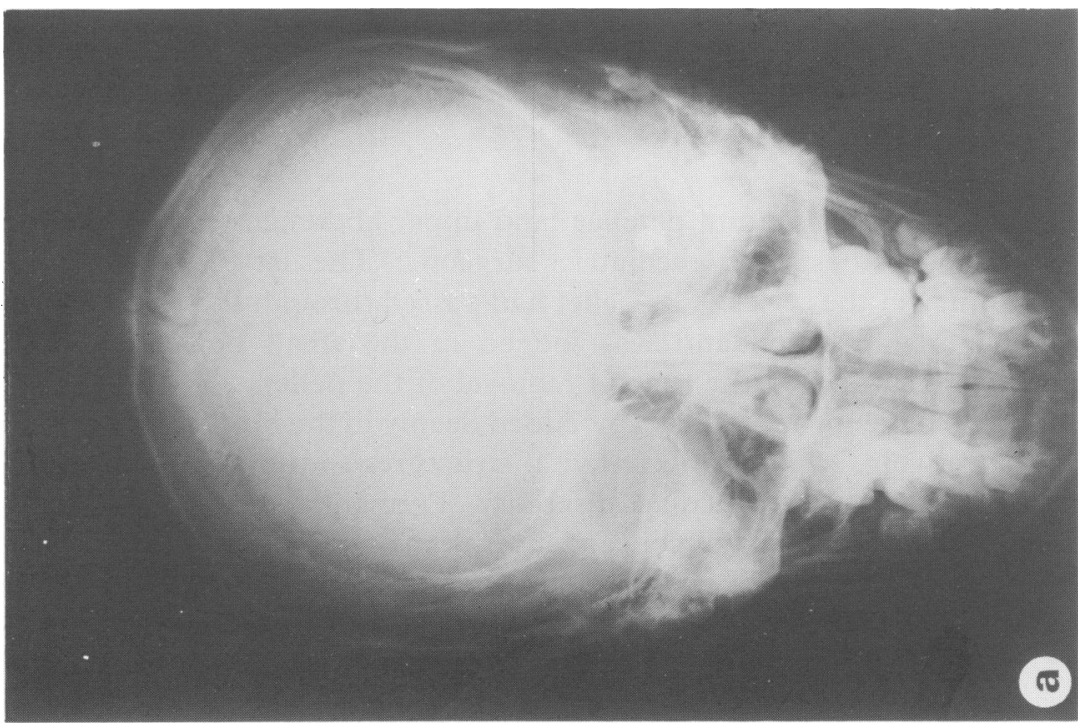

요

$\stackrel{2}{\overrightarrow{7}}$ 
22 W. Foan Robson and K. Kumar

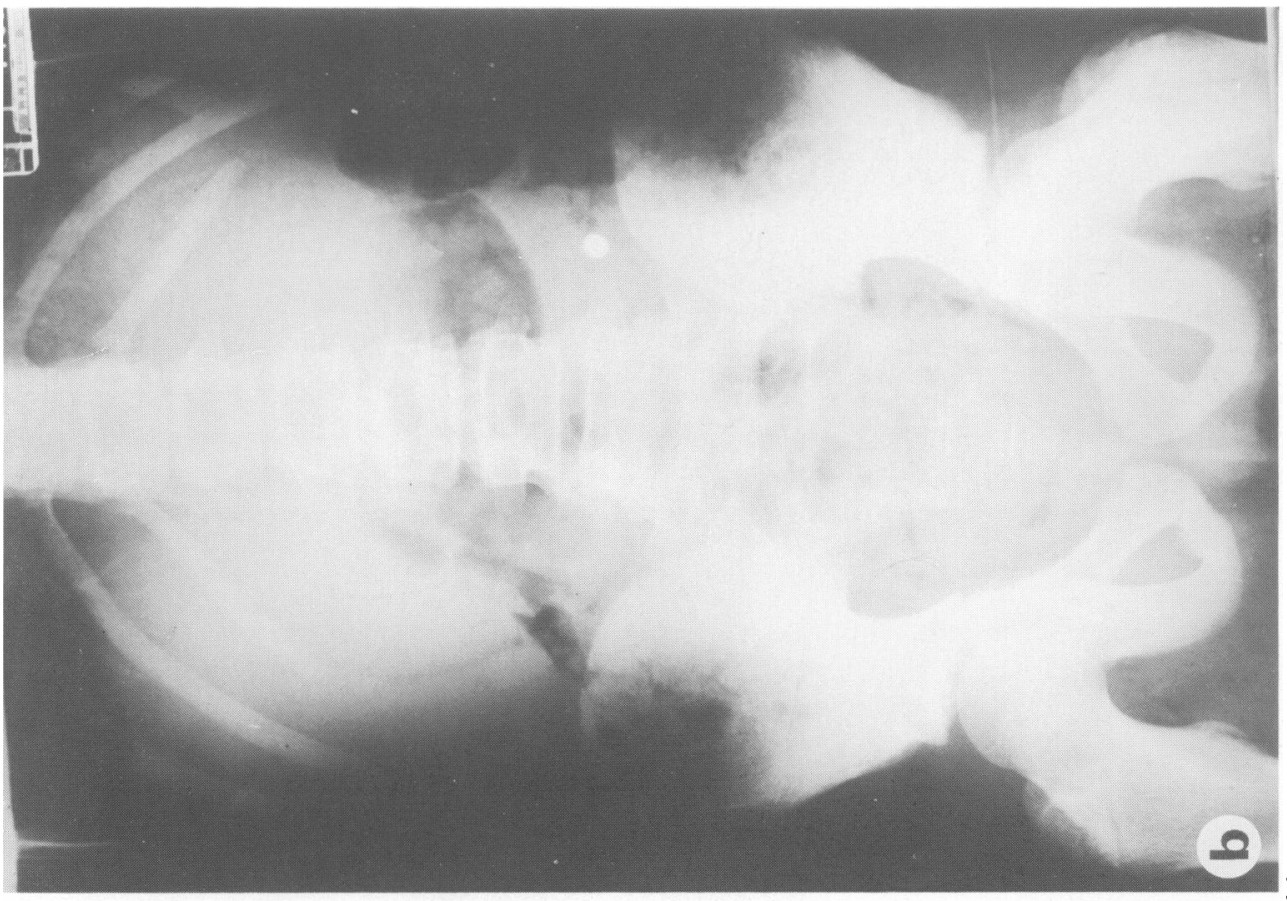

疋

\$

ㅇ.

$\overrightarrow{\overline{\mathrm{S}}}$

\%

믐

$\frac{\bar{c}}{\vec{D}}$

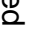

के

$\overrightarrow{0}$

$\overrightarrow{\overrightarrow{\vec{C}}}$

W

$\frac{3}{3}$

궁.

这

5

S.

蓉

兽

?

$\infty$

○

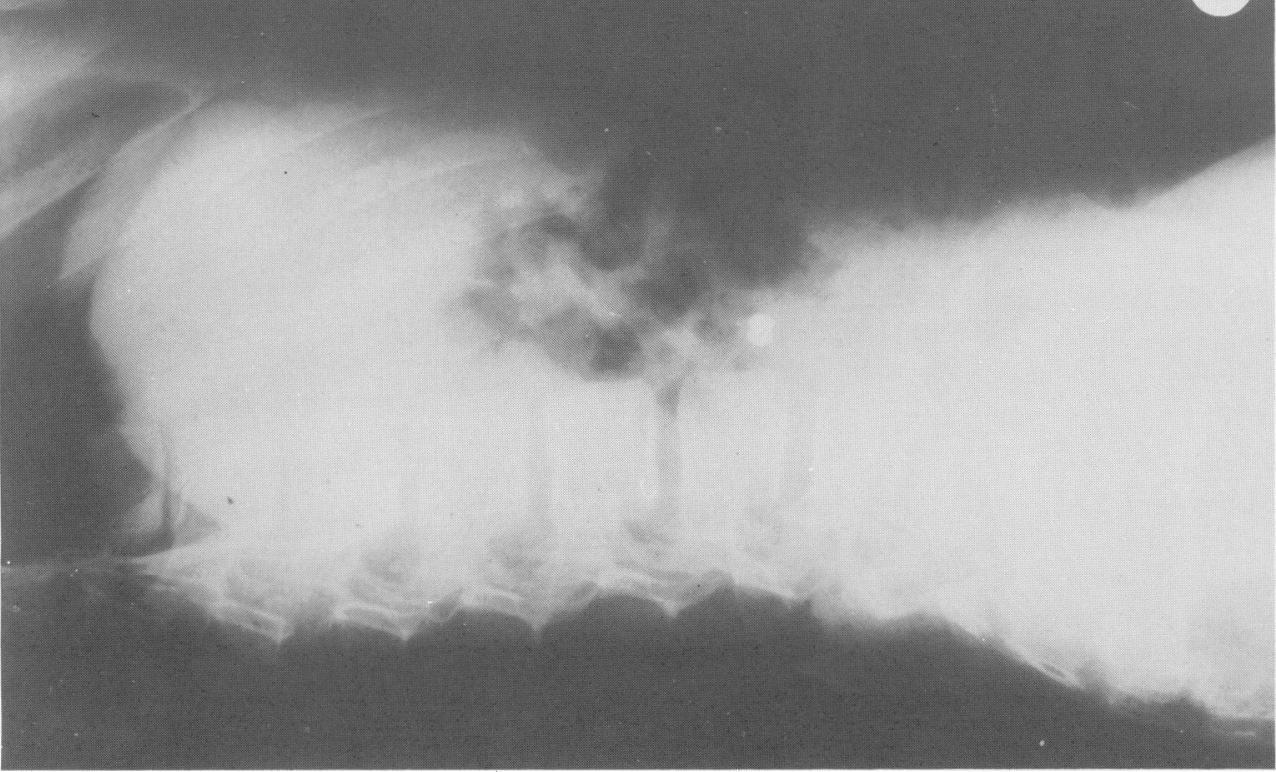




\section{DISCUSSION}

Although air weapon injuries are mainly classified as accidents, many are as a result of intentional shootings using humans or animals as targets or occur as a result of misuse of air weapons. The image of the air rifle or pistol is often that of a toy gun rather than a lethal instrument. Previous reports from this country have either concentrated on particular injuries (Bowen et al., 1973; Shaw et al., 1977; Batch, 1981; Cain et al., 1983), have been retrospective (Bowen et al., 1973; Hutchinson, 1981) or have studied only those patients who were admitted (Bowen et al., 1973). This preliminary report on a prospective study in a paediatric accident and emergency department with an annual new-patient attendance of 39000 gives a broader picture. In 6 months there were three orbital injuries, one penetrating facial injury and one penetrating abdominal injury. In the same period 10 other injuries of the head, neck and trunk occurred, all of which could have been life-threatening if the pellets had been fired with increased velocity. This can be achieved by 'dieseling'-oil is purposely sucked up into the barrel and is combusted by the heat generated as a pellet passes down the barrel. The resulting explosion increases muzzle velocity and consequent penetrating power (Buchanan, 1982). A further 13 limb injuries could have lead to permanent disability. Of the 28 injuries at least 20 arose out of incidents in homes or public places which were against existing guidelines for the safe use of air weapons (British Association for Shooting and Conservation, 1983). Other authors (Bowen et al., 1973; Batch, 1981) have stressed the need for better education in this field. Our analysis supports this view. We suggest that this education is best done through sporting associations publicising their guidelines to owners of air weapons.

At present the law is as follows.

(A) It is illegal:

to carry a loaded air weapon in a public place, without lawful authority or reasonable excuse;

to use an air weapon on private land without the owner's permission;

to possess or use an air weapon if you have been sentenced to any form of custody for a term of three months or more-you are prohibited for five years if the sentence was up to three years, and for life if the sentence was over three years;

to shoot at any bird or animal unless you are an authorized person as defined by the Wildlife and Countryside Act 1981;

to discharge an air weapon in the street or within 50 feet of the centre of a highway.

(B) Youngsters between 14 and 17:

may not buy or hire an air weapon, but can receive one as a gift or on loan;

may only have an air rifle (but not an air pistol) in a public place providing it is securely fastened in a cover which prevents it from being fired;

may not possess an air pistol unless in an approved rifle range or at a shooting gallery.

(C) Children under 14:

may not buy, hire, be given or otherwise own an air weapon;

may only carry an air rifle (but not air pistol) in a public place providing it is securely covered and they are supervised by a person over 21 ; 
may only use an air weapon in a private place, while supervised by a person over 21 ; may only use an air weapon providing they are supervised by a person over 21 , and must $\frac{\mathbb{D}}{0}$ not shoot beyond the premises on which the air weapon is being used.

If education fails to reduce the number of injuries then new legislation must be? considered.

\section{REFERENCES}

Batch A. J. G. (1981) The air rifle: a dangerous weapon. British Medical fournal 282, 1834.

Bowen D. I. \& Magauran D. M. (1973) Ocular injuries caused by airgun pellets: an analysis of 105 cases. British Medical fournal 1, 333-7.

British Association for Shooting and Conservation (1983) Sporting Air Rifle Shooting-A Code of Practice. British Association for Shooting and Conservation, National Headquarters, Marford Hill, Clwyd, North Wales.

Buchanan J. D. (1982) 'Dieseling'-a potentially lethal phenomenon in air weapons. Science and Law 22, $\stackrel{\text { N }}{\rightarrow}$ $107-10$.

Cain D. \& Weeks R. F. (1983) A new danger associated with airgun pellet injuries. British Medical fournal $286,21$.

Hutchinson G. H. (1981) Airgun pellet injuries in children. Practitioner 225, 1058-60.

Shaw M. D. M. \& Galbraith S. (1977) Penetrating airgun injuries of the head. British fournal of Surgery $64, \frac{3}{2}$ 221-4.

Received 6 fune 1984; editorial comments to authors 13 August 1984; accepted for publication 6 September $1984 \vec{\emptyset}$ 